\title{
The conundrum of deep vein thrombosis prophylaxis in burns in India and review of literature
}

\author{
S. S. Shirol, Srinivas Kodaganur, M. Raghavendra Rao', Vinaykumar Tiwari² \\ Department of Plastic Surgery, KIMS, Hubli, ${ }^{1}$ Department of Rehabilitative Medicine, HCG, Bengaluru, Karnataka, ${ }^{2}$ Department \\ of Plastic Surgery, RML Hospital, New Delhi, India
}

Address for correspondence: Dr. S. S. Shirol, Sampige Super Speciality Clinic, Club Road, Hubli - 580 028, Karnataka, India. E-mail: ssshirol@yahoo.co.uk

\section{ABSTRACT}

Objective: The aim is to assess the practice of deep vein thrombosis (DVT) prophylaxis among the plastic surgeons attending National Academy of Burns India Conference 2012 (NABICON 2012). Background: DVT prophylaxis in burns is a controversial issue as there is no consensus among the community of burn surgeons about the prevalence of DVT, the incidence of pulmonary embolism, the indications for DVT prophylaxis, dosage and duration of low molecular weight heparins (LMWH) and the complications related to DVT and LMWH. Methodology: A survey was conducted among plastic surgeons attending the NABICON 2012 held at New Delhi, by circulating a questionnaire. The respondents were divided into two groups based on whether burns constituted more than or less than $50 \%$ of their practice. The data thus collected were tabulated and analysed. Results: Almost $70 \%$ of all the respondents practice some form of DVT prophylaxis. There was significantly higher incidence of complications related to the use of LMWH among the surgeons whose practice of burns was $>50 \%$. There was no significant difference between the two groups in relation to the incidence and complication of DVT or recommendation of DVT prophylaxis. Conclusion: Majority of plastic surgeons practice DVT prophylaxis routinely and consider multiple criteria such as percentage of burns, age, lower limb involvement, the degree of burns and associated co-morbidities for starting the LMWH.

\section{KEY WORDS}

Burns; deep vein thrombosis; deep vein thrombosis prophylaxis in burns; low molecular weight heparins; National academy of burns India conference; survey

\section{INTRODUCTION}

eep vein thrombosis (DVT) prophylaxis in burns patients has always been a contentious issue. Burn injury results in the hypercoagulable

\begin{tabular}{|l|l|}
\hline \multicolumn{2}{|c|}{ Access this article online } \\
\hline Quick Response Code: & Website: \\
\hline & www.ijps.org \\
\cline { 2 - 2 } & Dol: \\
\hline
\end{tabular}

state due to increase in prothrombotic factors such as factors $\mathrm{V}$, factor VIII, platelet count and fibrinogen ${ }^{[1]}$ which increases the risk of DVT and fatal pulmonary embolism (PE). The American College of Chest Physicians (ACCP) guidelines published in 2008

This is an open access article distributed under the terms of the Creative Commons Attribution-NonCommercial-ShareAlike 3.0 License, which allows others to remix, tweak, and build upon the work non-commercially, as long as the author is credited and the new creations are licensed under the identical terms.

For reprints contact: reprints@medknow.com

How to cite this article: Shirol SS, Kodaganur S, Rao MR, Tiwari V. The conundrum of deep vein thrombosis prophylaxis in burns in India and review of literature. Indian J Plast Surg 2017;50:288-94. 
recommend DVT prophylaxis in burn patients with specific risk factors. ${ }^{[2]}$

The reported incidence of DVT in burn patients range from $0.25 \%$ to $23 \%$ in various case series, ${ }^{[3,4]}$ but various issues such as the actual incidence of DVT, the need for chemoprophylaxis, the duration, dosage and complications of low molecular weight heparins (LMWH) remain unanswered due to the absence of any randomised controlled trial.

We conducted a survey amongst plastic surgeons attending National Academy of Burns India Conference (NABICON) 2012 held in New Delhi, India, regarding the type of DVT prophylaxis in burns patients so as to get the data about the current practice in our country and as a positive step in the ultimate goal of formulating Indian guidelines for better care of patients suffering from burns based on the existing literature.

\section{METHODOLOGY}

This survey was conducted during the NABICON 2012 held at India Habitat Centre, New Delhi from February 3, 2012 to February 5, 2012 by circulating a questionnaire containing 20 questions [Table 1] among the delegates attending the conference.

The questionnaire was not announced before the conference, was distributed at the beginning of a scientific session in the forenoon on the $1^{\text {st }}$ day of the conference and collected back during the same session. This was done to prevent any discussion among the delegates and possible bias while answering the questionnaire.

Out of the 60 questionnaires' circulated, 46 participants responded. The data collected was then tabulated and the results were analysed for each question. The respondents were divided into two groups based on their response to question number 2. Group I consisted of respondents whose practice constituted $>50 \%$ of burns patients, we labelled them as Burns' surgeons and Group II were respondents whose practice constituted $<50 \%$ of burns patients and were plastic surgeons who practiced burns' regularly. Then, to test for the level of significance between the two groups, the Chi-square test was used to calculate the "p" value.

\section{RESULTS}

Among all the respondents, $68.2 \%$ of them practiced some form of DVT prophylaxis in their practice, whereas $75.2 \%$ in Group I and $64.3 \%$ in Group II practiced DVT prophylaxis, but this difference was not significant between the two groups $(P=0.468)$.

Only $40 \%$ of the respondents used a duplex scan to diagnose DVT; the rest preferred clinical methods, $41.7 \%$ in Group 1 and 38.9\% in Group 2 used duplex scanning, here again, the difference between the two groups was not significant $(P=0.681)$.

When the respondents were asked as to what factors they considered to be criteria for DVT prophylaxis in their practice (Q no 6), most of them $(72.7 \%$ ) responded that they would consider all the factors (age, \% of burns, comorbidities and type of burn) as criteria for starting DVT prophylaxis in any burn patient. Nearly $9.1 \%$ of respondents in the Group I said that they would consider age as a sole criteria, but none in Group II (0\%), whereas 5.6\% of respondents in Group II said that they would consider associated Comorbidities of the patient as a criteria for starting DVT prophylaxis and none of the respondents in the Group I considered associated comorbidities as a criteria.

The majority of the respondents $(79.3 \%)$ said that they would not use DVT prophylaxis in children (Group I-66.7\%, Group II-88.2\%, $P=0.158$ ).

Two-thirds (63.3\%) of the study participants opined that they would start DVT prophylaxis once the patient is haemodynamically stable, $36.7 \%$ wanted to start DVT prophylaxis on admission itself, there was no significant difference between the two groups in this aspect (Group I-61.1\%, 38.9\%, Group II-63.3\%, 36.7\%, $P=0.757)$.

When the participants were asked as to what modality of DVT prophylaxis they preferred, the majority of them $(70 \%)$ said that they would use a combined approach of prophylaxis that included chemo-prophylaxis, pneumatic compressionandcrepebandageapplication. Theresponses were similar between the two groups (Group I-75\% (all), 25\% (chemo alone), Group II-66.7\% (all), 5.6\% (pneum comp), 27.8\% (chemo alone) $P=0.684$ ).

The majority (73.3\%) of the respondents in this survey said that they would continue DVT prophylaxis only 
Table 1: Questionnaire

1. Do you practice Burns?
a. Yes b.
No

2. What percentage of your practice constitutes Burns? $\%$

3. Do you practice DVT prophylaxis in Burns?
a. Yes
b. No (If No go to question No. 20)

4. What is the incidence of DVT in Burns in your practice__ $\%$

5. How do you diagnose DVT in your practice?
a.
Clinical b.
Duplex Scan

6. What are the criteria for selecting DVT prophylaxis in your practice?
a. Age b. \% of Burns c. Co morbid conditions
d. Weight e. Type of burns (specify)

7. What is the minimum percentage of burns that you start DVT prophylaxis in your practice? $\%$

8. Do you use DVT prophylaxis in children with burns?
a.
Yes
b.
No

9. When do you start DVT prophylaxis?
a. At the time of admission
b. After hemodynamic stability

10. What is the modality of DVT prophylaxis do you use?
a. Chemoprophylaxis b.
Crepe bandage
c. Pneumatic compression d.

11. How long do you continue the prophylaxis?

$\begin{array}{ll}\text { a. } & \text { Specific period (_ } \\ \text { b. } & \text { Till the patient is ambulated } \\ \text { c. } & \text { Till the time of discharge }\end{array}$

12. Which molecule do you prefer using in DVT prophylaxis?

$\begin{array}{lllll}\text { a. Enoxaparin } & \text { b. } & \text { Rivaparin } & \\ \text { c. Dalteprin } & \text { d. } & \text { Bemiparin } & \text { e. }\end{array}$

13. What is the dose of L.M.W.H. you use in DVT prophylaxis?

14. Did you ever encounter morbidity/mortality related to DVT?
a.
Yes
b.
No

15. Did you ever encounter complication related to L.M.W.H.?
a.
Yes
b. No

16. Do you stop L.M.W.H. prior to surgery?
a.
Yes $\quad b$
No

17. Do you think L.M.W.H. dosage is to be adjusted based on $\%$ of burns?
a.
Yes
b.
No

18. Do you think L.M.W.H is under utilized in burn?
a.
Yes
b.
No

19. What do you suggest to promote DVT prophylaxis in burns?

20. Why do you think DVT prophylaxis is not required in burns? Kindly brief

Name:

Signature:

Address:

until the patient became ambulant, whereas others would continue DVT prophylaxis till discharge. (Gr. I-66.7\% (ambulation.), 16.7\% (discharge), 16.7\% (1 week.), Group II-77.8\% (ambulation.), 5.6\% (discharge.), $16.7 \%$ ( 1 week.), $P=0.603$ ).

The majority of the study participants has encountered morbidity related to DVT in burns patients (overall-76.7\%, Group I-75\%, Group II-77.8\% $P=0.860)$.
When participants were asked whether they have encountered any complication with LMWH, none of the respondents in Group II had experienced any complications, whereas $41.7 \%$ of respondents in the Group I had experienced complications with LMWH $(P=0.003)$.

The majority of the respondents feels that LMWH is underutilized in burns (overall-89.7\%, Group I-91.7\%, Group II- $88.2 \% P=0.765$ ) and also that it should be 
stopped before surgery (overall-73.3\%, Group I-75\%, Group II-72.2\% $P=0.866$ ).

Most of the respondents (62.1\% Group I-75\% Group II-52.9\% $P=0.228$ ) do not adjust the dose of LMWH depending on the percentage of burns. The results are tabulated as the questions with two answers as options [Table 2] and the questions with four answers as options [Table 3].

\section{DISCUSSION}

There is a paucity of data regarding DVT prophylaxis in burns' patients due to limited research on this subject. The ACCP 2008 guidelines recommend routine chemical venous thromboembolism (VTE) prophylaxis in burn patients with specific risk factors. These risk factors are as follows: older age, lower extremity burns, morbid obesity, associated trauma, the use of femoral central venous catheters or prolonged immobilisation. ${ }^{[2]}$

The National Burn Conference held in New Delhi was the ideal location to conduct this survey as it provided us a unique opportunity where the entire community of Burns' specialists of India would come together.

The rationale for dividing the respondents into two groups depending on how much of their percentage of practice constituted burns' patients was to ascertain whether the respondents whose practice

Table 2: Results for the questionnaire with two options as answers

\begin{tabular}{|c|c|c|c|c|c|c|c|}
\hline \multirow[t]{2}{*}{ Question number } & \multicolumn{2}{|c|}{$<50 \%$} & \multicolumn{2}{|c|}{$>50 \%$} & \multicolumn{2}{|c|}{ Combined } & \multirow[t]{2}{*}{$P$} \\
\hline & $A(\%)$ & B (\%) & $A(\%)$ & B (\%) & $A(\%)$ & B (\%) & \\
\hline 3 & 64.3 & 35.7 & 75.0 & 25.0 & 68.2 & 31.8 & 0.521 \\
\hline 5 & 61.1 & 38.9 & 58.3 & 41.7 & 60.0 & 40.0 & 0.879 \\
\hline 8 & 11.8 & 88.2 & 33.3 & 66.7 & 20.7 & 79.3 & 0.198 \\
\hline 9 & 38.9 & 61.1 & 33.3 & 66.7 & 36.7 & 63.3 & 0.757 \\
\hline 14 & 77.8 & 22.2 & 75.0 & 25.0 & 76.7 & 23.3 & 0.860 \\
\hline 15 & 0.0 & 100.0 & 41.7 & 58.3 & 83.3 & 16.7 & 0.003 \\
\hline 16 & 72.2 & 27.8 & 75.0 & 25.0 & 73.3 & 26.7 & 0.866 \\
\hline 17 & 52.9 & 47.1 & 75.0 & 25.0 & 62.1 & 37.9 & 0.228 \\
\hline 18 & 88.2 & 11.8 & 91.7 & 8.3 & 89.7 & 10.3 & 0.765 \\
\hline
\end{tabular}

constituted $>50 \%$ of burns patients, whom we could call as "burns" surgeons' were any different than other plastic surgeons whose practice constituted $<50 \%$ but treated burns on a regular basis with respect to their current knowledge on DVT prophylaxis in burns. The only significant difference between the two groups was in the area of complications related to $\mathrm{LMWH}$, where the plastic surgeons whose practice of burns was $<50 \%$ did not encounter any complication with $\mathrm{LMWH}$, whereas $41.7 \%$ of the burns' surgeons did.

Nearly $68.2 \%$ of the respondents in our survey practiced DVT prophylaxis in burns; this is in accordance with the recent survey of 84 burn centres in the United States revealed that $76.1 \%$ of these centres used some form of DVT prophylaxis. ${ }^{[5]}$ In our country where there are no existing guidelines regarding burns' management, our survey reveals an interesting finding that a majority of plastic surgeons considered DVT prophylaxis as necessary in burns' patients.

There is enough evidence to suggest that most of the DVT, which occurs in burns' patients, is asymptomatic and goes unnoticed by the physician. ${ }^{[4]}$ This has been exemplified by the fact that the incidence of DVT in retrospective studies is quite low $(<1 \%),{ }^{[6,7]}$ whereas in a small prospective study by Wahl et al. where all burns' patients were screened for DVT the incidence was as high as $23 \%{ }^{[3]}$ This difference can be attributed to the fact that in retrospective studies only symptomatic patients underwent duplex scanning.

In our survey, only $40 \%$ of the respondents preferred duplex scanning to clinical examination as the method to diagnose DVT. This is surprising as only $40 \%$ of patients with DVT manifest any clinical signs and duplex is mandatory to confirm the diagnosis of DVT. ${ }^{[8]}$

There is evidence from retrospective studies that there are specific risk factors for development of symptomatic DVT in burns' patients, Pannuci et al. have used the National Burn Repository of America (NBR) data to develop a predictive model for VTE which identifies many

Table 3: Results for the questionnaire with four options as answers

\begin{tabular}{|c|c|c|c|c|c|c|c|c|c|c|c|c|c|}
\hline \multirow[t]{2}{*}{ Question number } & \multicolumn{4}{|c|}{$<50 \%$} & \multicolumn{4}{|c|}{$>50 \%$} & \multicolumn{4}{|c|}{ Combined } & \multirow[t]{2}{*}{$P$} \\
\hline & $A$ & $B$ & $C$ & $D$ & $A$ & $B$ & $C$ & $D$ & $A$ & $B$ & $C$ & $D$ & \\
\hline 6 & 0.0 & 22.2 & 5.6 & 72.2 & 9.1 & 18.2 & 0.0 & 72.7 & 3.4 & 20.7 & 3.4 & 72.4 & 0.512 \\
\hline 10 & 27.8 & 0.0 & 5.6 & 66.7 & 25.0 & 0.0 & 0.0 & 75.0 & 26.7 & 0.0 & 3.3 & 70.0 & 0.684 \\
\hline 11 & 16.7 & 77.8 & 5.6 & - & 16.7 & 66.7 & 16.7 & - & 16.7 & 73.3 & 10.0 & - & 0.603 \\
\hline 12 & 96.43 & 0.0 & 0.0 & 3.57 & 100.0 & 0.0 & 0.0 & 0.0 & 97.73 & 0 & 0 & 2.27 & - \\
\hline
\end{tabular}


risk factors such as increased age, medical comorbidities, presence of inhalation injury, the need for intensive care unit (ICU) admission, increased number of ICU days, mechanical ventilation over $48 \mathrm{~h}$, increased number of operative procedures, and increased TBSA(Total Body Surface Area) ${ }^{[4]}$

The ACCP guidelines also recommend that the presence of specific risk factors mandates chemoprophylaxis. The majority of the respondents in our survey opined that they would consider all the risk factors (\% of burns, age, medical comorbidities, type of burn) as criteria to initiate prophylaxis, which is in accordance with the ACCP guidelines. However, Wahl et al. retrospective study showed that the risk factors enunciated by Pannuci et al. did not hold good in their subset of patients and that DVT developed in patients without any of those risk factors and the only two factors which increased the risk of DVT/NTE were the presence of lower extremity burns and infection of the burn wound. ${ }^{[8]}$

There are no existing guidelines regarding the timing and duration of DVT prophylaxis in burns patients. Lin et al. in their study have used nonambulation for $>48 \mathrm{~h}$ and ICU admission as criteria for starting DVT prophylaxis and prophylaxis was discontinued in their study when the patient was able to ambulate at least thrice a week or a distance of 125 feet. ${ }^{[9]}$

Conventionally for other indications such as major general/gynecological/orthopedic surgeries, the ACCP recommends prophylaxis for up to 35 days with LMWH and a minimum of 10 days. ${ }^{[2]}$ There are problems in using ambulation as criteria to stop DVT prophylaxis, first being that it is a subjective criterion and secondly, that DVT can develop even in the ambulatory patients. ${ }^{[10]}$

In our survey, the majority of the respondents opined that they would start DVT prophylaxis once the patient is haemodynamically stable. Even though this decision appears prudent in the authors' opinion, there is no evidence to back it up.

Chemical method of prophylaxis has been shown to be the most effective and LMWH is the drug of choice in the majority of the patients, ${ }^{[11,12]}$ except in certain circumstances where LMWH has been contraindicated, such as decreased creatinine clearance. Other methods come into play in combination with LMWH, or when LMWH has been contraindicated, these methods include graduated compression stockings, intermittent pneumatic compression devices, warfarin, fondaparinux and Vitamin $\mathrm{K}$ antagonists. ${ }^{[12]}$

In burns' patients chemoprophylaxis appears to be more suitable as the application of compression stockings and devices would be difficult if the lower extremity is involved. The ACCP guidelines recommend LMWH as the drug of choice. ${ }^{[11]}$ In cases of an increased risk of bleeding, the guidelines recommend mechanical thromboprophylaxis in the form of graduated compression stockings or intermittent pneumatic compression devices.

Most of the respondents in our survey used a standard dosage of $1 \mathrm{mg} / \mathrm{kg}$ of Enoxaparin twice daily for DVT prophylaxis. The ACCP recommends that clinicians need to follow the manufacturer's guidelines while deciding the dosage ${ }^{[2]}$ In the study by Lin et al. $30 \mathrm{mg}$ bid has been used for prophylaxis and $1 \mathrm{mg} / \mathrm{kg}$ bid as a therapeutic dose, but the same authors have proved that this tradition dosing is inadequate by measuring anti-factor Xa levels in severely burned patients and have devised a formula to calculate enoxaparin dosing which incorporates the TBSA and body weight.

(Enoxaparin dose $(\mathrm{mg}$ every $12 \mathrm{~h}$ ) $=22.8+3.3$ $\times(\mathrm{TBSA} / 10)+1.89 \times(\mathrm{wt} / 10) \cdot{ }^{[9]}$ However, further studies are needed to recommend routine clinical usage of this formula.

Causes of death after severe burn have changed over time; in the international literature, multisystem organ failure is seen as the most important cause, ${ }^{[13]}$ but $76.7 \%$ of the respondents in our survey have experienced morbidity/mortality related to DVT in burns' patients. This is in accordance with the data from prospective studies by Wahl et al. ${ }^{[3]}$

LMWH are relatively safe drugs, known complications include thrombocytopenia and increased risk of bleeding, allergic reactions, mild elevation of hepatic transaminases, osteoporosis, injection site abscess, or hematoma. LMWH are contraindicated if creatinine clearance is $<30 \mathrm{ml} / \mathrm{min}$ as they are excreted through the kidney. ${ }^{[14]}$

Nearly $41.7 \%$ of the study participants in Group I had encountered complications related to $\mathrm{LMWH}$ in our study; whereas none of the participants in the other group had encountered any morbidity with LMWH. This could be explained by the fact that the burns' surgeons 
had more experience in identifying complications of LMWH, although the explanation may not be completely satisfactory.

Although it may appear logical to stop LMWH before surgery, as $73.3 \%$ of our respondents' do, due to the fear of excess intraoperative bleeding, Recent evidence, however, suggests that the risk of developing a potential complication with LMWH has to be balanced against the potential for developing VTE in the particular patient. There are known reports of patient developing epidural hematomas who are on $\mathrm{LMWH}$, leading to neurological deficits. Hence, it is advised that for patients on anticoagulation, neuraxial blockade/subarachnoid block be given when the effect of the anticoagulant is minimal. ${ }^{[15]}$ Kearon et al. have recommended that it is necessary to stop LMWH $12 \mathrm{~h}$ before surgery. ${ }^{[16]}$

The conventional dosing of LMWH does not change with respect to percentage of burns, but Lin et al. in their study on enoxaparin dosing have used the TBSA as part of their formula, Harrington et al. in their study of 1300 thermally injured patients have concluded that the sum of age and TBSA has the potential to identify those group of patients at high risk of developing DVT/PE. ${ }^{[17]}$ Pannucci et al. in their analysis of the data from the NBR have shown that those patients with burns between $40 \%$ and $59 \%$ have the highest risk of developing DVT/VTE (2.4\%), whereas for those with higher TBSA $(<60 \%)$ the risk appeared to be lower. ${ }^{[4]}$ This could be due to physicians being more aggressive while treating salvageable burns $(<60 \%)$ or due to the higher chances of developing disseminated intravascular coagulation which could derail the clotting process in patients with $>60 \%$ burns or the patients died before they developed DVT and VTE. ${ }^{[18]}$

When our respondents were asked as to what they would suggest to promote DVT prophylaxis in burns, the suggestions were that it needs to be incorporated into the textbooks, more importance needs to be placed on them during conferences, and more multicentre studies were needed before promotion and also to maintain a high index of suspicion in burns' patients. The ACCP guidelines suggest that to increase adherence to thromboprophylaxis the use of computer decision support systems (Grade 1A), preprinted orders (Grade 1B) and periodic audit and feedback (Grade 1C). Passive methods such as the distribution of educational materials or educational meetings are not recommended as sole strategies to increase adherence to thromboprophylaxis. ${ }^{[2]}$
The available LMWHs approved for use in the U. S. include enoxaparin, dalteparin and tinzaparin. ${ }^{[19]}$ There are similarities as well as the difference between these molecules with respect to molecular weight, and biological action. However, enoxaparin is the most widely used and extensively available. ${ }^{[20]}$ White et al. in their review on LMWH have concluded that enoxaparin, dalteparin and tinzaparin have roughly comparable clinical efficacy in the treatment and prevention of VTE.

This topic has not been given its due importance in international conferences by various burns' association all over the world, for example, since 2013 the topic has appeared only in 9 abstracts, which forms $<2 \%$ of the total number of abstracts presented at the annual conference of the American burns' association. ${ }^{[21-23]}$ It is similar to the British Association, having no important session about DVT prophylaxis in burns' patients in their latest annual conference. ${ }^{[24]}$

This survey represents a small group of plastic surgeons of India who attended NABICON, and generalisation of the data are difficult. Other limitations of our survey were that the questionnaire did not include factor $\mathrm{Xa}$ assay and there were open-ended questions. The authors strongly feel the need for a simple protocol which includes various risk factors like $\%$ and degree of burns, lower limb involvement, age, obesity, wound infection, and other comorbidities to decide on starting the DVT prophylaxis and simpler formula to adjust the dosage of LMWH, which necessitates a large prospective multi-centric randomised control trials.

\section{CONCLUSION}

Majority of plastic surgeons who attended practice DVT prophylaxis routinely in adults but not in children and consider multiple criteria such as percentage of burns, age, lower limb involvement, the degree of burns, and associated comorbidities for starting the LMWH. However, there is no consensus about the dosage and duration of LMWH.

\section{Financial support and sponsorship}

Nil.

\section{Conflicts of interest}

There are no conflicts of interest. 


\section{REFERENCES}

1. King DR, Namias N, Andrews DM. Coagulation abnormalities following thermal injury. Blood Coagul Fibrinolysis 2010;21:666-9.

2. Geerts WH, Bergqvist D, Pineo GF, Heit JA, Samama CM, Lassen MR, et al. Prevention of venous thromboembolism: American college of chest physicians evidence-based clinical practice guidelines ( $8^{\text {th }}$ edition). Chest 2008;133:381S-453S.

3. Wahl WL, Brandt MM, Ahrns KS, Zajkowski PJ, Proctor MC, Wakefield TW, et al. Venous thrombosis incidence in burn patients: Preliminary results of a prospective study. J Burn Care Rehabil 2002;23:97-102.

4. Pannucci CJ, Osborne NH, Wahl WL. Venous thromboembolism in thermally injured patients: Analysis of the national burn repository. J Burn Care Res 2011;32:6-12.

5. Ferguson RE, Critchfield A, Leclaire A, Ajkay N, Vasconez HC. Current practice of thromboprophylaxis in the burn population: A survey study of 84 US burn centers. Burns 2005;31:964-6.

6. Fecher AM, O'Mara MS, Goldfarb IW, Slater H, Garvin R, Birdas TJ, et al. Analysis of deep vein thrombosis in burn patients. Burns 2004;30:591-3.

7. Wahl WL, Brandt MM. Potential risk factors for deep venous thrombosis in burn patients. J Burn Care Rehabil 2001;22:128-31.

8. Townsend C Jr., Beauchamp DR, Evers BM. Sabiston Textbook of Surgery. $6^{\text {th }}$ ed. New Delhi: Elsevier; 2011.

9. Lin H, Faraklas I, Saffle J, Cochran A. Enoxaparin dose adjustment is associated with low incidence of venous thromboembolic events in acute burn patients. J Trauma 2011;71:1557-61.

10. Sebastian R, Ghanem O, DiRoma F, Milner SM, Price LA. Pulmonary embolism in burns, is there an evidence based prophylactic recommendation? Case report and review of literature. Burns 2015;41:e4-7.

11. Geerts WH, Heit JA, Clagett GP, Pineo GF, Colwell CW,
Anderson FA Jr, et al. Prevention of venous thromboembolism. Chest 2001;119:132S-75S.

12. Cayley WE Jr. Preventing deep vein thrombosis in hospital inpatients. BMJ 2007;335:147-51.

13. Bloemsma GC, Dokter J, Boxma H, Oen IM. Mortality and causes of death in a burn centre. Burns 2008;34:1103-7.

14. Brunton L, Chabner B, Knollman B. Goodman \& Gillman's Pharmacological Basis of Therapeutics. $12^{\text {th }}$ ed. New York: McGraw-Hill; 2011.

15. Lumpkin MM. FDA public health advisory. Anesthesiology 1998;88:27A-8A.

16. Kearon $\mathrm{C}$, Hirsh J. Management of anticoagulation before and after elective surgery. N Engl J Med 1997;336:1506-11.

17. Harrington DT, Mozingo DW, Cancio L, Bird P, Jordan B, Goodwin CW, et al. Thermally injured patients are at significant risk for thromboembolic complications. J Trauma 2001;50:495-9.

18. Lippi G, Ippolito L, Cervellin G. Disseminated intravascular coagulation in burn injury. Semin Thromb Hemost 2010;36:429-36.

19. Drugs@FDA: FDA Approved Drug Products; 2015. Available from: http://www.accessdata.fda.gov/scripts/cder/ drugsatfda. [Last accessed on 2015 Sep 05].

20. Caprini JA, Arcelus J, Sehgal LR, Cohen EB, Reyna JJ. The use of low molecular weight heparins for the prevention of postoperative venous thromboembolism in general surgery. A survey of practice in the United States. Int Angiol 2002;21:78-85.

21. Proceedings of the American Burn Association 45 $45^{\text {th }}$ Annual Meeting. $1^{\text {st }}$ ed. Boston: Burn Science Publisher; 2013.

22. Proceedings of the American Burn Association 46 ${ }^{\text {th }}$ Annual Meeting. $1^{\text {st }}$ ed. Boston: Burn Science Publisher; 2014.

23. Proceedings of the American Burn Association $47^{\text {th }}$ Annual Meeting. $1^{\text {st }}$ ed. Chicago: Burn Science Publisher; 2015.

24. Convenus.com. 2015. Available from: http://www.convenus.com/ bba/. [Last accessed on 2015 Sep 05]. 